\title{
La filosofía en la ciudad: Alejandro Korn y las experiencias culturales del Grupo Renovación en una capital de provincia
}

\author{
Philosophy in the city. Alejandro Korn and cultural experiences \\ of Grupo Renovación in the capital of a province
}

\author{
Osvaldo Graciano*
}

\begin{abstract}
Resumen: Este artículo reconstruye las iniciativas culturales que promovieron en la ciudad de La Plata, capital de la provincia de Buenos Aires y sede de una de sus más importantes universidades, los estudiantes y profesores liderados por el magisterio del filósofo Alejandro Korn, entre 1918 y su muerte ocurrida en 1936. El grupo de universitarios que siguió a Korn se identificó con las ideas y propuestas del movimiento de la Reforma Universitaria y con el pensamiento de las corrientes filosóficas del espiritualismo y del idealismo que él les propuso, promoviendo en sus miembros prácticas culturales y formas innovadoras para la organización de su trabajo intelectual, entre las que se contaron el grupo discipular de influencia socrática, la publicación de revistas, el emprendimiento editorial y el teatro. Esa práctica intelectual les permitió proyectar su acción en la vida cultural de la ciudad e intervenir en su espacio literario y artístico y en la vida política del país, con singulares propuestas estéticas.
\end{abstract}

Palabras clave: Alejandro Korn, filosofía, cultura, Reforma Universitaria, socialismo.

\begin{abstract}
This article reconstructs cultural initiatives promoted in La Plata -capital of Buenos Aires Province and home to one of the most important universities- by students and faculty led by philosopher Alejandro Korn's teachings, between 1918 and his death in1936. The group of academics who followed Korn got identified with ideas and proposals of the University Reform movement and with the phylsophical thought of spiritualism and idealism currents proposed by him which promoted on their members cultural practices and innovative ways for organizing their intellectual work. Among them, there were the discipleship group of socratic influence, the publishing of magazines, the editorial venture and the theater. That intellectual practice allowed them to project their action in the cultural life of the city participating in its literary
\end{abstract}

\footnotetext{
*Argentino. Doctor en Historia, Investigador Adjunto del Consejo Nacional de Investigaciones Científicas y Técnicas (CONICET) y Profesor Asociado en la Universidad Nacional de Quilmes (Argentina). ograciano@unq.edu.ar

Este artículo fue desarrollado en el marco del Proyecto Universitarios, Artistas e intelectuales en la Argentina. Prácticas culturales, producción de saber y modos de intervención política, 1900-1975 de la Universidad Nacional de Quilmes y una versión preliminar se presentó en el Encuentro académico Arenas culturales. Por una historia cultural urbana sudamericana (UNQ/ IDES, Buenos Aires, 2013). Agradezco a los participantes de ese evento como también a los evaluadores anónimos de la revista sus comentarios y sugerencias que posibilitaron enriquecer mi artículo.
} 
and artistic space as well as in the political life of the country with unique aesthetic proposals.

Keywords: Alejandro Korn, philosophy, culture, University Reform, socialism.

Recibido: 28 junio 2016

Aceptado: 7 diciembre 2016

\section{Introducción}

La muerte de Alejandro Korn el 9 de octubre de 1936 en su casa de la ciudad de La Plata significó la desaparición de un filósofo que encarnó para sus contemporáneos la figura socrática de un Maestro en la Argentina de entreguerras. Sus colegas y discípulos universitarios que lo acompañaron en su hora final lo despidieron recordándolo como un Sócrates contemporáneo. Un "Maestro de saber y virtud” según la oración fúnebre que le dedicó el escritor dominicano Pedro Henríquez Ureña. La prensa periódica y las revistas culturales difundieron su deceso en extensas notas que cubrieron su sepelio y los homenajes tributados retomando la evocación del Maestro socrático. ${ }^{1} \mathrm{Y}$ sin dudas Korn hubiera aprobado esa rememoración pública de su figura como la de un filósofo griego, ya que durante su ejercicio como profesor universitario se había investido a sí mismo el papel de un magisterio en la cultura académica argentina. Ese magisterio tenía además una dimensión política sobriamente ejercida por Korn entre sus discípulos en la década del '20 y abiertamente manifestada desde 1931, momento en el que ese papel intelectual se amplió a la ardua tarea de incidir en la vida política nacional a través de su afiliación al Partido Socialista.

Este artículo analiza las iniciativas culturales que promovieron en La Plata los estudiantes y profesores liderados por el magisterio de Alejandro Korn desde 1920 hasta su muerte e indaga en los vínculos intelectuales que las sostuvieron. La práctica cultural que desplegaron encontró su posibilidad de realización en una ciudad que sobresalía por su condición de universitaria y fue la Reforma Universitaria, el movimiento de protesta estudiantil de cuestionamiento de la práctica educativa y científica dominante en las casas de altos estudios en los años 1918-1920, el "catalizador" del desarrollo de esa experiencia. El grupo de universitarios que siguió a Korn se identificó con las ideas y propuestas predicadas por el reformismo, a las que su magisterio socrático contribuyó a dar contenido, promoviendo también en sus miembros vínculos y formas innovadoras para la organización de su trabajo intelectual, entre las que se contaron la publicación de revistas, el

\footnotetext{
${ }^{1}$ Esta cobertura puede seguirse en los diarios El Día y El Argentino de los días viernes 9 y sábado 10 de octubre de 1936 y en Claridad. Revista de Arte, Crítica y Letras. Tribuna del pensamiento izquierdista, Año XV, octubre-noviembre de 1936, números 306-307. Interpretaciones de la muerte socrática de Korn en Rodríguez Alcalá (1954: 229-245) y Halperín Donghi (2000: 93).
} 
emprendimiento editorial y el teatro, que les permitió proyectar su acción en la vida cultural de la ciudad e intervenir en su espacio literario y artístico con singulares propuestas estéticas. El magisterio entre el filósofo y los estudiantes que lo aceptaron y acompañaron, sustentó esas iniciativas que fueron legitimadas por ellos en la prédica del arielismo, posibilitándoles una intervención intelectual que se proyectó en la moderna urbe que era La Plata y que cimentó su práctica cultural en la difusión del idealismo y el espiritualismo y en la recreación del humanismo clásico e hispánico, reivindicándolos como fundamentos de la cultura argentina en la primera posguerra. Su muerte clausuró la trayectoria cultural y política de un grupo de universitarios iniciada dos décadas antes, que había dado lugar a una sociabilidad intelectual de vínculos discipulares en la ciudad y que lo tuvo como su principal mentor. La bibliografía sobre el Grupo Renovación y el teatro universitario en La Plata limitó sus enfoques al análisis de la revista y del grupo escénico que fundaron borrando las situaciones histórico-políticas de sus diversos momentos como también los contextos urbanos en las que esas iniciativas se inscribieron. Su consecuencia fue la incomprensión de esas experiencias como expresión de un movimiento intelectual y artístico amplio fundado en un posicionamiento filosófico que remitía a una circunstancialidad urbana y a una historicidad nacional y mundial precisa que inscribían a sus actores. ${ }^{2}$ Aquí se reconstruye esa experiencia intelectual colectiva en su despliegue histórico y urbano.

\section{Un Maestro y la definición de una "Weltanschauung" para la acción colectiva}

Korn se convirtió desde la emergencia del reformismo universitario en uno de sus principales líderes intelectuales. Su carrera académica se había consolidado ya antes de 1918, al ser designado profesor de las cátedras de Historia de la Filosofía en las Facultades de Filosofía y Letras porteña y de Ciencias de la Educación platense. Su incorporación en 1917 a la Academia de Filosofía y Letras reforzó el reconocimiento institucional de su condición de filósofo. Korn se arraigó en La Plata desde 1914, en una casona de planta única ubicada a escasas cuadras de la universidad. Su hogar fue el lugar decisivo en la configuración de las relaciones que fue estableciendo con los estudiantes y profesores al margen de la cátedra y su biblioteca se constituyó en su lugar de estudios, el de formación intelectual de sus hijos y el centro de las reuniones con sus estudiantes, colegas y discípulos. Frente a bibliotecas universitarias y públicas parsimoniosas en la incorporación de las novedades intelectuales y en las que persistían los autores decimonónicos institucionalizados en la enseñanza oficial, la del filósofo les ofrecía a aquellos un lugar único para el acercamiento a las literaturas y las filosofías espiritualistas y neoidealistas, que enseñaba y recomendaba en sus clases, donde accedían a los escritores que primaban en la posguerra como Bergson, Croce y Dilthey en su lengua (Ranea, 2002: 119-136). Era también el lugar íntimo en donde se reconocía la amistad como valor social que fundaba

\footnotetext{
${ }^{2}$ La bibliografía sobre el tema es además escasa. Al respecto véanse Rodríguez (1999: 217-247); Rodríguez,
} \& Vasquez (2002), Sánchez Distasio (2005: 45-86) y Graciano (2008). 
esa relación discipular, el ámbito que consagraba la íntima relación Maestro-discípulo. En el espacio público sus vínculos con los estudiantes y profesores reformistas se desplegó como una sociabilidad cuyo punto de partida era su cátedra, tenía instancias en las caminatas por las avenidas y parques de la ciudad, en los encuentros en restaurantes, cafés y librerías, en actos universitarios, en los banquetes y agasajos a intelectuales en el Jockey Club y en la redacción del diario El Argentino, en los que el trato personalizado se fundaba en la condición del discipulado y la valorización de la amistad masculina. ${ }^{3}$

Fueron pocos los profesores que como Korn alcanzaron tempranamente una estima intelectual extendida entre diversos grupos de estudiantes y un posicionamiento importante en lo académico antes de las protestas estudiantiles de 1918. Su vinculación con el reformismo potenció su designación en cargos de dirección de la universidad: decano de la Facultad de Filosofía y Letras porteña entre 1918 y 1921, consejero superior de esa Universidad en 1922 y de la platense entre 1920-1921. A partir de ese momento Korn encontró en la cátedra, en las revistas culturales, en la Academia de Filosofía y Letras y en el vínculo con los distintos grupos de estudiantes y jóvenes egresados que le reconocían su condición de maestro de filosofía (los del Ateneo Universitario, los de la Asociación de ex alumnos del Colegio Nacional de La Plata, los del Colegio Novecentista), los espacios intelectuales de una labor docente y filosófica que no consideró limitada a la enseñanza de los programas de sus cátedras, sino que concibió como la de elaborar una nueva filosofía. Ya en sus cursos de los años de la Guerra europea indicó con insistencia el agotamiento del positivismo como pensamiento que fundaba la cultura y la dirección de la sociedad. Sus ensayos El momento actual de la filosofía (de incorporación a la Academia de Filosofía y Letras) e Incipit vita nova (publicado en 1918 en Atenea), plantearon que en las letras y la filosofía aparecían los signos de renovación portados por León Tolstoi, Paul Verlaine, Anatole France, John Ruskin, y formuló el desafío de forjar una nueva orientación filosófica idealista para la época, cuyas balizas de pensamiento debían ser Immanuel Kant, Federico Nietzsche, Benedetto Croce y Henri Bergson (Korn, 1918: 13; Halperín Donghi, 2000: 55-73; Eujanian, 2001: 83 - 105).

Con estos filósofos los universitarios argentinos debían según Korn superar la perimida filosofía positivista (naturalista y mecanicista) y elaborar otra de "orientación ética" para el presente, recuperando la condición de autonomía y de libertad ética del sujeto, con las cuales construir una personalidad sin sujeciones y dueña de su propio destino histórico (Torchia Estrada, 2011: 39-40). Iba a encontrar en el Nietzsche de Así habló Zaratustra al filósofo que había dado una "orientación axiológica" a la filosofía y que había formulado en las ideas del superhombre y de la voluntad de poder las directrices de pensamiento para la acción intelectual emancipada de sus discípulos. Así afirmaba en Incipit vita nova interpretando al filósofo alemán: “...Es mi voluntad la que arbitrariamente fija los valores de la existencia” (Korn, 1918: 11). Idea que ampliaba en su ensayo La libertad creadora sosteniendo:

\footnotetext{
${ }^{3}$ Su hija Inés y su discípulo Arnaldo Orfila Reynal describieron en escritos de homenaje estas modalidades de sociabilidad practicada por Korn (Orfila Reynal, 1943: 6; Korn, 1960).
} 
Nietzsche vio claro en este punto y quiso substituir la libertad de vivir por la "voluntad de poder", condición de desarrollo de un tipo humano superior. Este concepto empero se presta a una interpretación torpe, que jamás estuvo en la mente del autor, a pesar de su afectado inmoralismo. La voluntad de poder no es otra que la de actualizar la libertad en toda su plenitud, porque en el hombre la voluntad de vivir, se ha elevado a la voluntad de vivir libre (Korn, 1922: 50).

Zaratustra fue la figura que promovió entre sus discípulos y estudiantes, modelo del superhombre que afirmaba su existencia y acción libre en el mundo. El mismo Korn era ese anacoreta imaginado por Nietzsche que había hecho su formación intelectual autodidacta en las nuevas tendencias filosóficas vitalistas en la reclusión del Hospicio de Alienados que dirigió como médico por diez años y que en los tres textos filosóficos antes citados, les anunciaba a sus estudiantes la crisis de la cultura occidental y su manifiesto papel de actuar en el mundo como los creadores de los valores culturales que consideraran pertinentes frente a esa nueva realidad histórica. Korn sin embargo no siguió a Nietzsche en el desenvolvimiento último de su pensamiento (que llevó a aquél al nihilismo) y las ideas que fundamentaron sus ensayos filosóficos para crear los valores para el pleno desenvolvimiento de la personalidad fueron las de Kant y fundamentalmente las de Bergson. Los jóvenes universitarios eran quienes podían ser los superhombres, convertirse en los creadores de una nueva cultura humanista para una sociedad en la que se afirmara su libre existencia. El ensayo de Korn La Libertad Creadora fue el programa filosófico sobre el que se asentó la acción del grupo Renovación. Bergson le posibilitaba a Korn un programa filosófico para la liberación de la personalidad humana:

Actualizar la libertad absoluta por la conquista del dominio económico sobre la naturaleza y del autodominio ético, someter la necesidad a la libertad, alcanzar el pleno desarrollo de la propia personalidad, he ahí la meta, no impuesta por poderes extraños, no inventada por la fantasía, como que es la raíz misma del devenir (Ibid., 73).

En la crisis universitaria Korn fue empoderado por el reformismo como representante de sus demandas de cambio educativo y cultural, a las que encauzó a través de su propuesta de renovación de la enseñanza universitaria y en particular de la filosofía. En parte esas demandas se concretaron con su decanato de la facultad de Filosofía y Letras y con su participación como consejero superior en la UNLP y en la UBA, gestiones en las que impulsó el recambio de sus profesorados, la creación de nuevas cátedras y la modificación de planes de estudios (Buchbinder, 1997; Coll Cárdenas, 2005: 50-54). Pero para Korn se trataba de un programa de acción intelectual de escala más vasta porque debía comprometer en esa renovación a toda la cultura nacional. La acción intelectual del filósofo excedía así la labor de la cátedra y el recinto de la universidad, debiendo lanzarse a la ciudad, tomarla como el espacio en donde producir esa innovación de las ideas y valores sociales que guiaban la vida política de los ciudadanos y fundaban sus gustos literarios y estéticos. Ya en 1917 en Corrientes de la Filosofía contemporánea, había reclamado frente a la crisis de la cultura occidental por una filosofía vinculada a "la vida real" e, interpretando a Dilthey, 
que fuera una "Weltanschauung”, una “...concepción eficiente del mundo y de la existencia, una Weltanschauung, que sea fuerza viva en nuestro espíritu, norma de nuestra conducta y resorte ideal de la acción colectiva." (Korn, 1949: 351).

La crisis universitaria era una oportunidad de su renovación como alto instituto de dirección de la cultura del país, como así también lo era para sus intelectuales, quienes como hombres de ideas según Korn, debían asumirla como un mandato impostergable. Pero el diagnóstico del filósofo del estado de crisis histórica que se vivía no se limitaba a lo cultural sino que se extendía también a lo que consideraba la crisis del orden político burgués en Europa, debido a los profundos cambios sucedidos allí con la caída de las monarquías centrales y la revolución bolchevique. Era a su entender la crisis del régimen liberal, a la que lo condujo un capitalismo sustentado en la ideología del liberalismo manchesteriano. Su culminación fue una guerra que culminó con el hundimiento de la sociedad burguesa. En la Argentina esos cambios políticos mundiales afectaban según Korn su propio orden ideológico y cultural y si bien su desenvolvimiento político no tenía los ribetes violentos europeos, el paso desde 1912 de un régimen liberal de oligarquías a una democracia política de masas y de partidos políticos, implicaba a su entender consecuencias de primer orden: su funcionamiento sin principios y valores políticos por la crisis del positivismo y del liberalismo. En el incumplimiento de ejercer el papel de minorías de saber que interpretaran los problemas culturales e ideológicos de la sociedad en la nueva hora y fijaran nuevos rumbos ideológicos por derivarse en disputas internas y por encerrarse en su acción científica y educativa "escolástica" de cátedra, encontraba Korn otro dato fundamental de esa crisis.

Ese era el diagnóstico intelectual del filósofo tanto de la experiencia histórica que vivía el mundo como de la democrática abierta en el país y en él complejizaba las preocupaciones que Rodó había expuesto para la juventud americana en su Ariel en 1900: las que tenían que ver con el proceso de un capitalismo que reificaba a los sujetos como cosas en sus relaciones sociales y conllevaba su formación en el materialismo y el utilitarismo que empobrecía la experiencia humana y el de una democracia de masas que encerraba el riesgo de la nivelación social por el principio del igualitarismo de todos sus ciudadanos (Real de Azua, c. 1985: XV y XVI). Ambos procesos, el del capitalismo y el de la democracia traían como riesgo el aniquilamiento de la personalidad humana en una concepción utilitaria de la vida, sin valores e ideales éticos y estéticos que la orientaran y el hundimiento de la vida cultural de la sociedad por el predominio de la mediocridad del número (Rodó, 1985: 1-56).

Si la democracia como régimen político era el orden social inexorable en la coyuntura de la posguerra para el desarrollo de la experiencia humana, debía para Korn fundarse en nuevos principios filosóficos. Como Rodó, propuso frente a la cosificación del sujeto y a su masificación mediocrizante, la edificación de una cultura humanista cuyo agente era la juventud. Apoyándose en los estudios sobre arte de Benedetto Croce encontró en la elaboración de una cultura estética por parte de los estudiantes la respuesta adecuada al problema de la masificación y a la nivelación social que el capitalismo y la democracia 
producían, promoviendo estas iniciativas de la cultura letrada y artística en la ciudad. ${ }^{4}$ Ellas expresarían las nuevas ideas filosóficas para la sociedad luego de su profunda crisis derivada de la guerra y el agotamiento del positivismo.

Para el desempeño de esa tarea intelectual Korn confiaba en su despliegue colectivo como expresión de una voluntad grupal de los jóvenes que incidiera en las manifestaciones culturales citadinas y que era concebida por él y sus discípulos como la ya señalada "misión" de las minorías de saber en la formulación de los ideales éticos y estéticos para esas mismas minorías, para su sociedad y para la democracia de masas que se había impuesto como dato de la realidad argentina y que implicaba su responsabilidad social en la educación política del pueblo, en tanto que actor decisivo de esa experiencia como intelectual y como ciudadano. Pero a diferencia de Rodó, Korn asumió el liderazgo de esa misión y movilizó los lazos y vínculos intelectuales para ella con un sector de estudiantes y profesores reformistas durante la coyuntura del conflicto universitario, experiencia decisiva que les posibilitó desplegar una actuación cultural que tomara como su sujeto interpelado a la ciudad y a sus habitantes. Lo relevante era la concepción de Korn de la filosofía como saber de la sociedad y del filósofo como el ciudadano que la cultivaba en respuesta a las demandas de aquella. Esa concepción se expresó en la vinculación estricta que estableció entre filosofía e ideología: esta última era la portadora en la sociedad de los principios y valores éticos que aquella debía aportarles, para darle dirección a sus instituciones políticas y culturales e intervenir en la formación ciudadana y estética de su pueblo (Korn, 1949: 359-363). En crisis el positivismo como filosofía de un tiempo histórico que expresó sus tendencias y fuerzas sociales y dio orientación por medio del liberalismo a la sociedad, a su cultura y su política, el desafío de los filósofos debía ser formular otra filosofía que fundara una nueva ideología que la sustituyera para cumplir ese papel social. Para Korn, la tarea de la filosofía era dar respuesta a los problemas de la polis antes que circunscribirse a la labor intelectual de la cátedra. La Libertad Creadora fue su concepción del mundo y de la existencia, el programa fundamento de sus iniciativas culturales para desplegar en la ciudad por los estudiantes y profesores nucleados en Renovación. ${ }^{5}$

De las huelgas y protestas por la reforma de los estatutos y la enseñanza, de las frustraciones por las limitaciones académicas y educativas que enfrentaron, estos grupos reformistas pasaron a la acción cultural en la ciudad. Su consecuencia fue así la constitución en 1922 del Grupo de Estudiantes Renovación, quienes se propusieron el despliegue de un programa cultural en la ciudad, de promoción en ella de las "bellas artes", a través de la organización de una compañía de teatro, la publicación de una revista de cultura y la creación de un sello editorial. Toda una misión social de las minorías del saber.

\footnotetext{
4 “Por mi parte -y les llamo la atención sobre esto-, tengo una preferencia por la estética de Croce...”, afirmaba en sus clases (Korn, 2011: 406).

${ }^{5}$ La Libertad Creadora tuvo una amplia difusión entre los grupos estudiantiles. Su primera versión se publicó en 1920 en la revista Verbum del Centro de Estudiantes de Filosofía y Letras de Buenos Aires, circulando también ese mismo año como folleto editado por la Imprenta Araujo Hnos. Su segunda edición ampliada fue encargada en 1922 por su autor con el doble propósito de fundar la constitución del lazo discipular con los miembros de Renovación y de brindarle un manifiesto que funcionara como dirección intelectual del grupo.
} 


\section{Por una nueva cultura estética en la ciudad: el teatro de arte}

Estas iniciativas culturales se desplegaron en una ciudad definida por su modernidad burguesa y de gran presencia inmigrante europea, sin reminiscencias coloniales y criollas aunque tampoco patricias: de bulevares y avenidas, de magnificentes palacios gubernativos y educativos y de institutos científicos y universitarios cercados por jardines, de plazas y parques diseñados según el higienismo decimonónico y con un puerto sobre el Río de la Plata abierto al comercio de ultramar. Tampoco era una urbe obrera: su planificación logró concentrar las actividades ferroviarias, industriales y portuarias a gran distancia de la ciudad y en ellos emergerían los barrios de trabajadores, alejados del perímetro cívico burgués, ajenos a cualquier participación permanente en sus instituciones escolares universitarias (Lobato, 2004: 41-68). La ciudad había surgido en 1880 como el ensayo de un proyecto urbanístico de nueva metrópolis cultural y política para la Nación por medio de la aplicación de los saberes e instituciones letradas y científicas, que realizara las promesas de construir una sociedad y una cultura modernas en el desierto pampeano (Vallejo, 2007: 27-207).

Una comunidad universitaria que con sus instituciones y presencia en las calles predominaba en la ciudad, creando en sus universitarios la sensación de ser así el sujeto privilegiado de su vida social y cultural, contribuyó a la construcción del imaginario de una ciudad universitaria, que la prensa periódica estilizó en sus páginas. Los institutos académicos alimentaron una creciente actividad intelectual citadina y una sociabilidad educativa desplegada por profesores, científicos, profesionales y estudiantes argentinos, latinoamericanos y europeos, que asoció a ella a otros actores del mundo de la cultura letrada y no universitaria, como fueron los maestros del sistema escolar público, las redacciones de los periódicos, las modestas imprentas, las casas editoras y librerías, los teatros, bibliotecas, ateneos y clubes sociales, que actuaron como cenáculos de esa sociabilidad posibilitando su desenvolvimiento cotidiano y su extensión urbana. ${ }^{6}$ Pero esa celebrada función de "ciudad universitaria", fue en realidad una deriva histórica del frustrado destino inicial de gran urbe metropolitana, condición que resignó ante Buenos Aires. Atraída por la dinámica económica y cultural de la capital nacional, La Plata no adquirió rango de urbe internacional abierta al mundo, "resignándose" a las funciones administrativas de capital de provincia. La ausencia en ella de un movimiento comercial y social como el que caracterizó a Buenos Aires le permitió entonces distinguirse como un recinto urbano apacible para el desenvolvimiento de la cultura científica y la enseñanza profesional, una condición que la modernidad porteña aún con la universidad más importante del país y un gran movimiento cultural no podía ostentar. ${ }^{7}$

El grupo Renovación fue liderado inicialmente por el estudiante reformista y profesor de Literatura en la Facultad de Humanidades platense Héctor Ripa Alberdi.

\footnotetext{
${ }^{6}$ En 1918 los egresados del Colegio Nacional que fundaron la revista de letras, artes y filosofía Atenea signaron su labor intelectual como expresión de la "joven ciudad universitaria", reforzándola con la asociación idealizada de una urbe que rememoraba por sus institutos de ciencia y por la arquitectura de algunos de ellos (como el Museo de Ciencias Naturales), una Atenas rioplatense.

${ }^{7}$ Buenos Aires era para 1914 una ciudad de 1.575.814 habitantes y La Plata contaba con 137.413 para esa misma fecha (República Argentina. Tercer Censo Nacional, 1916: Tomo I, 116; Gorelik, 2010).
} 
Proveniente de Juárez, un pueblo agrícola de la provincia de Buenos Aires, fue uno de los líderes del reformismo estudiantil en la Universidad platense y fue privilegiado por Korn como su discípulo aventajado. Del interior rural bonaerense era también el estudiante Aníbal Sánchez Reulet, aunque la presencia dominante en el grupo fue de jóvenes platenses como en los casos de Carlos Américo Amaya, Luis Aznar, Pedro Verde Tello, Arnaldo Orfila Reynal, Adolfo Travascio, Carlos Sánchez Viamonte y Guillermo Korn (hijo este último del filósofo). Si bien el grupo mostraba diversidad en su formación profesional ya que algunos eran abogados, otros artistas plásticos, profesores y químicos, todos se reconocían en su condición de jóvenes reformistas actores de un cambio generacional, provistos en sus mochilas de la propuesta filosófica vitalista de su Maestro. Alejados desde

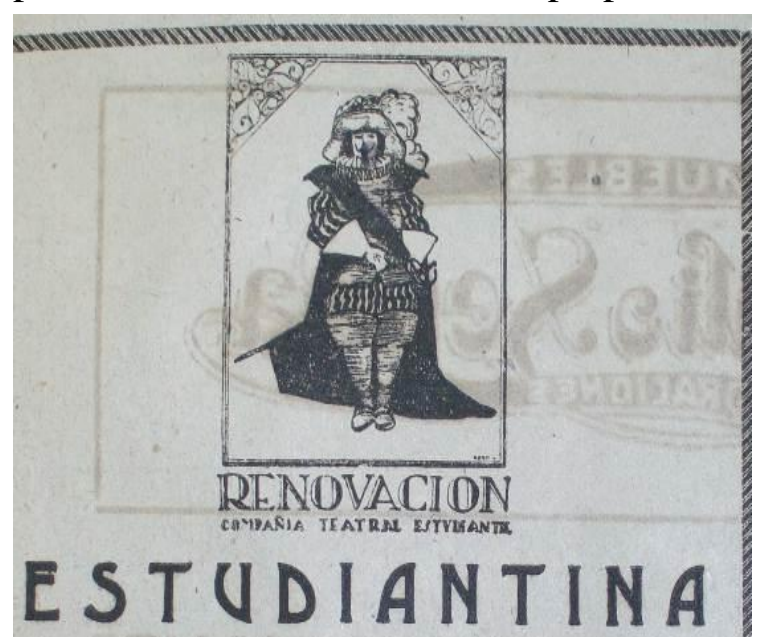

Esta noche, a las 21 en punto, en ei

TEATRO ARGENTINO

Donaires y piruetas y idanzas \& cantares,

Flores, versos, mujeres; la total armonia;

es la máscara antigua, bs lu viefa alegrfa

de ómicos alegres y pallidos ju glamea

Hacia el ciclo se eleva nua' vez cristaltena

y bay fragancla de brosas on tropel do carreira.

iCantadi que baja el aroo triunlal de Primaver

va cantando su fiesta la loca estudiantina.

LA POSADERA-Comedia en tres actos de Carlos Goldoni.

AA CLEVA DE SALAMANCA-Entrmes de Cervantos.

POESIAS-Himna de las Estudtantes.

La función dará comienzo a las 21 en punto

1921 de las luchas universitarias debido a que la dirección de la universidad platense fue retomada por sectores conservadores del profesorado liderados por el abogado Benito Nazar Anchorena (rector entre 1921 y 1927), fundaron la Compañía Teatral Estudiantil Renovación a la que se integraron otros universitarios, todos actores vocacionales cuya formación en actuación era la escolar (Sánchez Distasio, 2005: 71-74; El Argentino, 21 de septiembre de 1921: 1) Bajo la dirección del joven reformista Guillermo Korn el grupo puso en escena el 20 de septiembre de 1922 La posadera (en italiano La locandiera) de Carlo Goldoni, comedia de 1753 en la que el dramaturgo veneciano retrató de modo humorístico y transgresor a la sociedad aristocrática italiana a través de los vínculos entre Mirandolina, una joven plebeya dueña de la posada y tres nobles que la pretendían. Junto a ella estrenó La cueva de Salamanca de Miguel de Cervantes Saavedra, un entremés cómico sobre los enredos y engaños en el matrimonio de Leonarda y Pancrasio. Como refiere la Ilustración $\mathrm{n}^{\circ} 1$, la representación teatral se cerró con el recitado de poesías y el canto del Himno de los Estudiantes.

Ilustración n⿳1: Publicidad de función teatral Grupo Renovación Fuente: Diario El Argentino.

La compañía inauguró así en La Plata de modo formal, la primera experiencia de teatro estudiantil universitario, llevándola adelante en su mayor sala lírica el Teatro Argentino y pretendiendo el reconocimiento de teatro artístico, en una cartelera teatral dominada por los espectáculos ofrecidos por compañías profesionales con sus programas de 
variedades, de comedias y sainetes y por los cinematógrafos que con su tecnología de la imagen revolucionaban las artes escénicas (Sánchez Distasio, 2005: 45-72). Si bien su publicidad en los periódicos revelaba su vínculo con la tradición de la Estudiantina universitaria como celebración típica del día del estudiante (y que sucedía en la ciudad todos los 21 de septiembre), la puesta en escena de La Posadera significó la ruptura con esa tradición, convirtiéndose así en la plataforma para el lanzamiento de un teatro de arte y social por parte de Renovación, independiente de esas celebraciones. ${ }^{8}$

Teatro de arte puro no contaminado por lo mercantil y teatro para educar al pueblo en sus gustos por un espectáculo inspirado en aquél, teatro como expansión de la personalidad creadora, eran los objetivos de su programa artístico. La compañía afirmaba que para cumplirlos "Echaremos mano, por lo tanto, del teatro moderno y del antiguo." Esos lineamientos artísticos implicaban también la intención del grupo de convertirse en un teatro de actores profesionales, al adoptar la forma de una compañía teatral y definir un repertorio escénico singular. Autores clásicos como Cervantes y Goldoni o modernos como Benavente les posibilitaron cumplir esos objetivos estéticos como asimismo los propósitos político-culturales del reformismo universitario, lo que lograron sólo un mes después, el 16 octubre de 1922, cuando la compañía llevó a escena también en el Teatro Argentino, el drama de 1905 Hacia las estrellas de Leónidas Andreiev. Se trató en realidad de una apuesta artística-político ya que su función fue realizada en homenaje a la delegación del gobierno mejicano encabezada por José Vasconcelos e integrada entre otros escritores y artistas, por el crítico literario dominicano Pedro Henríquez Ureña, enfatizándose la confraternidad latinoamericanista a que daba lugar. Según el programa de la función, la representación del drama del escritor ruso que refería al fracaso de la revolución de 1905 y a la situación de desorientación y desánimo de la intelligentsia, buscaba simbolizar el idealismo intelectual que orientaba la tarea cultural del grupo Renovación y la experiencia de su propia frustración en la transformación de la Universidad: "Hacia Las estrellas de Andreiev, representa simbólicamente las dos direcciones que toma todo ideal humano: una que se desvanece en el conocimiento y en el deseo de lo absoluto y otra que torna sus ojos a la tierra afirmando los valores de la vida" (Korn, 1963: 284).

Se trató en realidad, de un reconocimiento y vínculo entre intelectuales, un acontecimiento universitario que se inscribía en uno de los ámbitos escénicos de la ciudad, convirtiéndolo al mismo tiempo en una experiencia de extensión cultural y de fraternidad latinoamericanista. Como informó en su primera plana el diario El Argentino, era a la vez un homenaje a los intelectuales mexicanos por parte de Renovación y una experiencia de "comunión espiritual" entre las juventudes universitarias de ambos países. El encuentro tenía como antecedente el vínculo que los delegados estudiantiles reformistas habían construido con Vasconcelos y Henríquez Ureña en México el año anterior, con su participación en el Congreso Internacional de Estudiantes y fue decisivo para la radicación

\footnotetext{
${ }^{8}$ Este mismo grupo de estudiantes había llevado a escena Los intereses creados de Jacinto Benavente en el Teatro Podestá de La Plata el 21 de septiembre de 1921, una presentación realizada bajo los auspicios de la Federación Universitaria y la Asociación de Ex alumnos del Colegio Nacional, integrando los eventos de celebración del Día del Estudiante. Actuaron en la obra Carlos Américo Amaya, Guillermo Korn, Luis Aznar y Pedro Verde Tello (El Argentino, miércoles 21 de septiembre de 1921: 1; Korn, 1963: 282).
} 
sólo dos años después del profesor dominicano en La Plata y de su nombramiento como profesor de su Colegio Nacional. ${ }^{9}$

En los años 1923-1924 y como se comprueba en la Ilustracion $\mathrm{n}^{\circ}$ 2, la compañía amplió sus puestas en escena con los entremeses de Lope de Rueda y la comedia de Molière El médico a palos, llevando otra vez a escena La posadera de Goldoni. Si tomaba por un lado el repertorio del teatro clásico, por otro lado adaptó obras de escritores contemporáneos como La verdad de Benavente y Retazo del ítalo-argentino Darío Nicodemi y de profesores universitarios como Enrique Herrero Ducloux con La línea recta. Su repertorio tenía una definida identidad universitaria, resultado de la labor del espacio de literatura de su Colegio Nacional con el papel clave que allí tuvieron primero los profesores reformistas José Gabriel López Buisán y Luis Juan Guerrero y luego Henríquez Ureña. El grupo teatral reforzó esa identidad al integrar nuevos estudiantes a su elenco y anunciar la

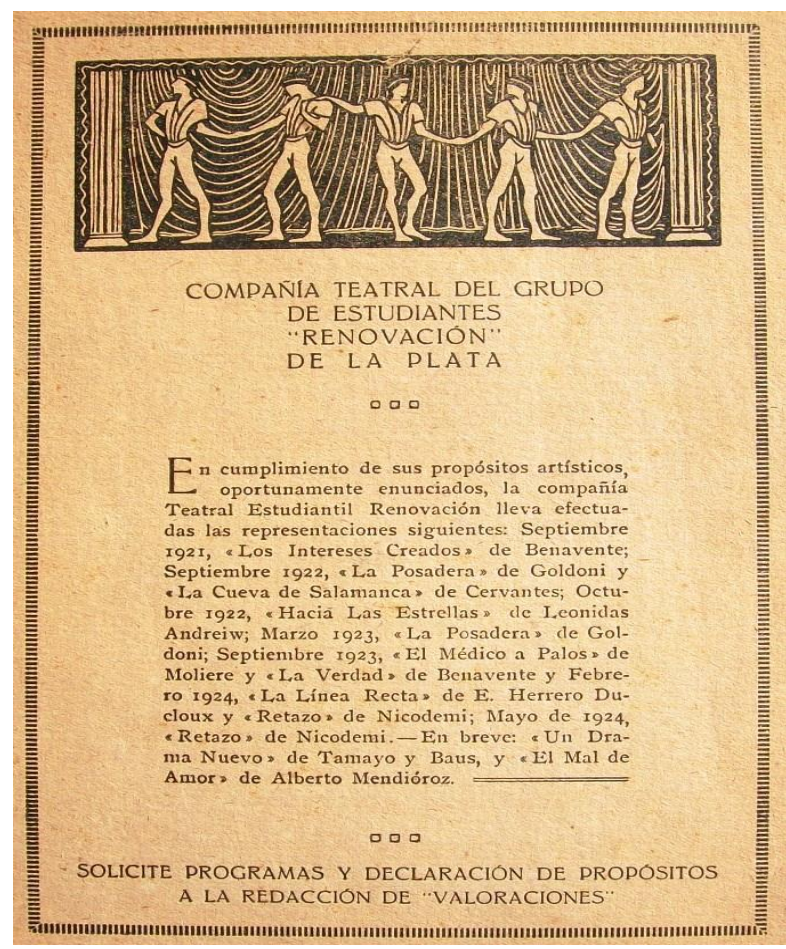
futura puesta en escena de obras de universitarios reformistas como El mal de amor de Alberto Mendióroz. Se trataba de un repertorio escénico en contrapunto marcado con los programas artísticos de las compañías profesionales, inclinadas a las obras de costumbres, dejando claro la diferencia que existía entre su teatro y el que consideraban expresión de un espectáculo mercantilizado y sin valor artístico. Pero si bien el teatro universitario difícilmente podía competir en modificar el gusto estético de los habitantes de la ciudad (configurado por la oferta de esas compañías) lograba su cometido de extensión universitaria y como demuestra su propia publicidad reproducida en la Ilustración $\mathrm{n}^{\mathrm{o}} 2$, ofrecía una efectiva alternativa de espectáculos a los platenses con una apuesta escénica que se pretendía libre de la mercantilización de la obra de arte y era una opción artística también frente a la cartelera cinematográfica dominada por las películas estadounidenses. abril 1924.

Ilustración no 2: Publicidad Compañía Teatro Renovación Fuente: Valoraciones. Año I, No III,

En 1926 la compañía intentó una nueva propuesta estética y se renombró como Teatro de Arte Renovación, buscando profundizar la experimentación y la práctica actoral vanguardista, a partir de influencias europeas muy disímiles, como podían ser las del teatro

\footnotetext{
9“Los intelectuales mexicanos serán objeto de un homenaje por el Grupo Estudiantil Renovación que se realizará hoy en el Teatro Argentino", El Argentino, 16 de octubre de 1922; (Biagini, 1999: 196-198).
} 
zarista con Bakst y Nijinsky, el proletario soviético, el del escenógrafo inglés Gordon Craig y el del austríaco Max Reinhardt, pasando por el dramaturgo alemán Georg Kaiser, el rusofrancés Pitoëff, hasta llegar al futurista italiano Anton Giulio Bragaglia. La condición cultural platense en la que se situaban, periférica no sólo a Europa sino también a la metrópolis cultural que ya era Buenos Aires, hacía posible apropiarse sin reservas estéticas de apuestas escénicas de tradiciones de teatro tan diversas y experimentar con ellas. Pero también en esa apropiación quedaban de lado preocupaciones económicas caras a las compañías de actores profesionales en sus puestas en escena, como era el indispensable éxito de público. En su carácter de teatristas cuyo laboratorio de recepción y apropiación era teórico porque se ubicaba en la universidad y no en el espacio del espectáculo teatral platense (en la competencia por la taquilla con las otras compañías), su búsqueda artística podía desligarse del condicionamiento propio de toda empresa teatral, priorizando lo estético por sobre lo comercial, lo que les posibilitaba adaptar obras y ponerlas en circulación con absoluta libertad de experimentación. Esto se hizo evidente con la representación del drama de George Bernard Shaw Santa Juana en el escenario del Colegio Nacional, que contó con la escenografía del pintor Adolfo Travascio. Allí el grupo lanzó su nuevo programa-manifiesto:

El teatro abandona la aburrida pesadez de los realistas y cobra nuevas formas. Pedimos ayuda a la farsa, con su alegre tinglado, que representa una tradición; al arte puro, quizás salvaje; a productos lejanos, pero no despreciables. El ballet ruso planteó el problema a principios de nuestro siglo. Elaboró nuestras conciencias de hombres jóvenes. Tenía las energías indomadas de lo natural, sin retórica. La sobriedad de Bakst, las magnificencias de Nijinsky. Desde entonces hombres audaces se han puesto a la obra: Gordon Craig, en Inglaterra; Kaiser y Reinhart, en Alemania; Bragaglia, en Roma; Pitoieff [sic], en Francia, han inquietado los espíritus afinados. Rusia, después de la Revolución, trabaja para crear un teatro proletario. Y sus esperanzas no serán defraudadas. En todo esto no hay pirotécnica. Se trata de aliviar la escena envejecida, devolverle su agilidad (Korn, 1963: 285).

Este manifiesto estaba influido por Henríquez Ureña y probablemente escrito por él, ya que reproduce los lineamientos escénicos que reclamaba para superar el realismo en el teatro moderno en su artículo Hacia un nuevo teatro publicado en Valoraciones (número 9 de marzo de 1926). Ureña asesoró en la puesta en escena del drama de la joven campesina católica francesa, que pudo ser también una de las primeras representaciones en el país de la obra del escritor irlandés, ya que había sido estrenada en inglés en 1923 y la compañía de Guillermo Korn la llevó a escena en octubre de 1926. Shaw con Santa Juana les posibilitaba arrogarse constituirse en la expresión del “...teatro de vanguardia, del teatro independiente porque es la creación que quiere renovar ante todo" (Programa Teatro de Arte Renovación, Valoraciones, $\mathrm{n}^{\mathrm{o}}$ 10, 1926: VI).

Pero el hecho que realizaran estas funciones en un escenario universitario evidenció que se marginaban del circuito teatral y cinematográfico citadino convocante del gran público y en cuyo espacio había pretendido influir en su gusto estético, ofreciéndole originalmente un teatro alternativo al denostado como mercantil. Su público no podía ser 
otro que el conformado por estudiantes, profesores y egresados de la misma universidad. El talón de Aquiles del teatro Renovación residía en su desatención de los desafíos que enfrentaban año a año las compañías de actores profesionales: asegurar su viabilidad comercial con el éxito de taquilla, garantizando con ello público, prensa, disponibilidad de salas y la propia profesionalización de sus actores estudiantes. Las pretensiones artísticas de introducir el expresionismo alemán de Kaiser y Reinhardt fueron más voluntad teórica que práctica y la escenografía de Santa Juana preparados por el pintor Travascio parecían influidos en sus formas más por el expresionismo del cine alemán que por el teatral. Así, la pretensión del grupo de refundar el teatro platense dando a conocer el teatro sintético contemporáneo, revisitar el castellano anterior a Lope de Vega y el de Shakespeare, recrear las tragedias griegas y las pantomimas y bailes criollas, eran un deseo intelectual de renovación completa de la escena teatral argentina más que una posibilidad de llevarlo a término. El hecho que no se registren nuevos espectáculos de la compañía hacia finales de la década del '20, revelaba más sus dificultades materiales y humanas para montarlos que un agotamiento de sus propuestas escénicas.

Para Alejandro Korn el teatro de Renovación desplegaba la cultura estética idealista de su propuesta filosófica, por lo que tenía de experiencia humanista clásica y por aunar en su concreción a las bellas artes (dramaturgia, poesía, música, pintura, danza) posibilitando la formación artística en ellas de sus propios discípulos (al llevarla adelante como actores) y también de quienes se acercaran a presenciar sus espectáculos, liberados de la mercantilización que sufría el arte en el teatro profesional. Korn infundió en sus discípulos esta visión de un arte sin contaminación, de un arte por el arte pero profundamente interesado por lo humano para la formación de la personalidad, en un mundo que la sometía según él a su masificación. Y si bien guardó cierta distancia actuó como mecenas ante las necesidades del grupo de financiar sus espectáculos. Lo que era claro para él y sus discípulos era que esta propuesta estética recuperaba la tradición del humanismo clásico y era acorde con una ciudad aún dominada por los lenguajes y signos de la cultura letrada y artística decimonónica, pero que ya aparecían amenazados por el de los nuevos medios de comunicación masivos. En efecto, la consolidación en esos años de los nuevos lenguajes artísticos expresados por el cine y la radio no fueron vistos por ellos como un peligro para la difusión artística que proponían o que implicaran una mengua de la cultura letrada e impresa. Sí creían que no alcanzaban el valor de un arte escénico como el que configuraba el teatro ni poseían su capacidad pedagógica de trasmitir valores idealistas al ciudadano. Se trataba de una creencia extendida en los grupos académicos ya que en esos mismos años la Universidad platense llevó adelante la extensión del humanismo y de las artes clásicas y creó institutos para su estudio como el Instituto de Teatro Griego en 1923 y la Escuela de Bellas Artes en 1924 (Vallejo, 1999: 113-152). Pero a la vez fundó en 1924 la primera estación radiofónica en la ciudad, orientándola a la difusión de conferencias culturales y ciclos de música clásica.

También debe remarcarse que se trataba de propuestas distintas en su experimentación del humanismo: mientras para Renovación las bellas artes debían servir como fundamento de la personalidad de los estudiantes haciendo factible la renovación idealista de la cultura argentina, las propulsadas por la universidad enfatizaban esa formación humanista a sus fines educativos instrumentales de ampliación de su preparación 
profesional-disciplinar. Sin embargo mucho también las unía y era que tanto las iniciativas culturales de Renovación como las de la Universidad expresaron una valoración sin fisuras del arte y de los saberes letrados y clásicos como centros de organización de la cultura de posguerra, en las que estaba ausente una evaluación del impacto que en la creación artística del nuevo siglo y en los ciudadanos alcanzarían la radio y el cine, que se convertirían en verdaderas industrias de la comunicación y el ocio culturales.

\section{Lo letrado en la nueva cultura citadina: Valoraciones y editorial Renovación}

Al mismo tiempo el grupo Renovación editó la revista Valoraciones. Humanidades. Crítica y Polémica. Su bibliografía señaló ya su condición de pubicación del espacio universitario reformista y latinoamericanista, de la vanguardia artístico-literaria y de intervención política a través del espacio cultural (Rodríguez, 1999: 217-247; Rodríguez; Vasquez, 2002). La revista en sus doce números editados entre 1923 y 1928, fue un intento de experimentación y divulgación tanto estético-literario como filosófico, con propósitos de renovación cultural humanista e idealista que sus editores propusieron llevar a término y que se elaboraba al margen de la universidad. En su primer editorial señalaban: "Esa nueva fantasía y ese nuevo pensamiento que nos llegan traídos por una amplia y poderosa corriente de humanismo, hemos de recoger en estas páginas, afirmando así, sobre una sólida base idealista, nuestra posición estética y filosófica" (Valoraciones. Humanidades. Crítica y Polémica, 1923, Año I, no 1: 3).

Con una cuidada edición, desde sus primeros números (el primero apareció en septiembre de 1923) Valoraciones difundió artículos sobre la filosofía, la ciencia y la estética "para batir la influencia positivista que respira, en general, toda la cultura argentina": desde Benedetto Croce, a Heinrich Rickert, Wilhem Windelband y Eugenio D’ors, pasando por un número dedicado a Kant, siendo Ortega y Gasset y Bergson los pensadores angulares del grupo celebrados en sus páginas y escritores como Romain Rolland fueron el puente para la búsqueda cultural en la India de la filosofía de Rabindranath Tagore. La revista se convirtió también en un espacio de difusión expectante de los jóvenes escritores y poetas. Jorge Luis Borges, Carlos María Onetti y Alfonsina Storni publicaron allí y su sección bibliográfica ocupó un lugar importante en la difusión de las “nuevas letras y autores" argentinos, europeos e hispanoamericanos.

La colaboración en ella de Henríquez Ureña con sus trabajos de crítica literaria, estética y escénica fue programática para la acción teatral del grupo y para la formación intelectual de sus miembros. Pero un punto alto de la publicación lo constituyó la amplia difusión de las artes plásticas. Sus números contaron con la edición de cuidadas láminas con reproducciones de pinturas que mostraban la novedad y el vanguardismo, que iban desde el cubismo de Emilio Pettoruti (Retrato de mi amigo, La dama del vestido violeta, I Ballerini) a las obras murales del mejicano Roberto Montenegro en los edificios públicos de su país (El árbol de la ciencia), pasando por las pinturas del ecuatoriano Camilo Egas (Raza india, La máscara del sol), del argentino Adolfo Travascio (La catedral, Naturaleza muerta) el uruguayo Pedro Figari y sus pinturas de recuperación del pasado rioplatense 
popular de tradición negra (El gato, Candombe) y las esculturas de Pablo Curatella Manes (Mujer Posando y Las Tres Bañistas).

Valoraciones se constituyó en una revista de pensamiento y cultura humanista, artística y literaria, hecha por universitarios pero no académica aunque tensionada por la experiencia educativa de la universidad platense, sobre la que tuvo una sistemática mirada crítica. Fue un ensayo de búsqueda de referencias filosóficas, literarias y artísticas, vanguardistas algunas y clásicas otras. Esencialmente fue el instrumento de un ejercicio intelectual formativo para los miembros de Renovación. En su edición debieron definir una propuesta de publicación, buscar y seleccionar autores y obras a difundir y comentar, establecer vínculos con otras revistas e intelectuales, criticar autores y artistas, posicionarse frente a acontecimientos políticos o hechos que afectaban a intelectuales, ejercer su crítica de la situación universitaria y asegurar las condiciones materiales para su impresión y circulación. Fue un espacio de realización de sus armas de escritura y de crítica, de posicionamiento político antiautoritario y de reivindicación de libertades civiles y políticas $\mathrm{y}$ en donde publicaron sus primeros ensayos sobre arte, literatura, cine y teatro. Pero las nuevas estéticas en ella convivieron con la reivindicación de las corrientes tradicionales del novecientos y sin dudas en el punto en que se mostró como vehículo de la vanguardia fue en la difusión de los nuevos escritores como Borges, de pintores como Pettoruti y escultores como Curatella Manes, y sin dudas fue portadora del vitalismo con la traducción de Carlos María Onetti de Bergson y con su trabajo Du Coté chez Proust (Valoraciones, 1925, no 7: 33-46).

Ese espacio de aprendizaje del trabajo intelectual letrado que fue Valoraciones, se expandió al de las ediciones cuando el grupo fundó la Editorial Renovación, orientada a publicar autores inéditos en español que ampliaran su proyecto de extensión cultural. Su pequeño catálogo de obras anunciadas en la publicidad de Valoraciones, más que el efectivamente publicado, daba cuentas de la predominancia de obras de literatura y teatro social europeo de preguerra, que iban desde el escritor italiano Roberto Bracco, los rusos Nicolai Gogol, Antón Chejov y Leónidas Andreiev y de quienes ya eran escritores reconocidos en el cambio de siglo pero adquirieron una influencia determinante durante la posguerra entre los jóvenes reformistas, como los franceses Romain Rolland y Henri Barbusse. Entre aquellos que efectivamente fueron publicados en 1924, se encontraron Fatalidad de Barbusse y Relato de un desconocido de Chejov, traducidos directamente del francés por el grupo estudiantil y con precio de tapa de un peso. Como puede observarse en la Ilustración $\mathrm{n}^{\mathbf{0}} 3$, las obras del catálogo daban cuenta en realidad de predilecciones estéticas por los relatos breves realistas y de connotaciones profundamente humanas, características de los cuentos de Chejov y de Barbusse traducidos, aunque como el grupo dejaba claramente expuesto en Valoraciones, Barbusse o Rolland expresaban su búsqueda de nuevas certezas ideológicas y políticas a partir de la crisis cultural abierta con la barbarie de la guerra europea y la revolución bolchevique.

La intención de publicar al joven líder político indio Mahatma Gandhi remitía también a esta búsqueda de alternativas ideológicas y éticas frente a la crisis y el eclipse cultural de la "brújula europea" como señaló Henríquez Ureña, aunque se llegaba al mismo a través del europeo Rolland, de quien habían logrado que autorizase la publicación de su Vie de Tolstoi y creían que haría lo mismo con su Vie de Gandhi. Así esa búsqueda de 
referencias intelectuales exploraba en "otra" Europa: no en la de los valores culturales de la barbarie de la guerra, sino en aquella que la exponía en su crudeza y buscaba afanosamente otros para su renovación.

Ilustración no 3: Publicidad editorial Renovación

Fuente: Valoraciones $\mathrm{n}^{\mathrm{o}} \mathrm{II}$.



Las ediciones de Renovación se desplegaban en la confrontación literatura de arte / literatura comercial: acercar al lector ediciones inéditas en español y con cuidadas traducciones del propio grupo universitario, de lo que consideraban las grandes obras universales, con el mismo propósito de dilatar la labor de extensión cultural de su teatro. Fue un modo de intervención en el mercado del libro que al igual que con los espectáculos teatrales consideraban que debía ofrecerse al público una literatura de calidad estética, alternativa al de las novelas pasatistas y los folletines semanales, buscando influir en la oferta literaria y brindar otro canon de lecturas. El grupo Renovación no apeló inicialmente a difundir en su editorial a jóvenes o a consagrados escritores, que sí encontraron en Valoraciones difusión (Ricardo Guiraldes, Carlos M. Onetti, Francisco López Merino y Julio Noé entre otros). La edición mayor del grupo fueron las Obras de Héctor Ripa Alberdi, que reunieron en dos tomos los discursos, ensayos, críticas y poemas del líder estudiantil de Renovación y principal discípulo del viejo Korn, cuya sorpresiva muerte en 1923 (contaba con 26 años de edad) había resentido de un liderazgo clave al grupo y al movimiento estudiantil. La publicación era el homenaje póstumo al malogrado poeta y universitario y un reconocimiento de la importancia de su obra y acción intelectual al frente de la revista y de la compañía estudiantil (Ripa Alberdi, 1925). Asimismo las ediciones del sello se dirigieron también a difundir las posiciones filosóficas de Alejandro Korn, de quien publicaron en 1922 uno de sus ensayos claves, La Libertad Creadora. Su publicación consumaba la proyección de Korn de profesor de filosofía en la universidad a filósofo de la ciudad y fue en esa década y en esa relación discipular cuyo continente era Renovación, que produjo sus principales textos filosóficos, difundidos por sus discípulos entre el estudiantado. Pero las limitaciones materiales le impidieron al grupo sostener su proyecto editorial ya que no pasó de un pequeño número de obras. Era evidente que en una cultura impresa que se regía por el mercado, no organizar su proyecto como una empresa editorial implicaba el riesgo de no pasar de las buenas intenciones.

Alejandro Korn pasaría a ocupar un primer plano en Renovación al asumir la dirección de Valoraciones en mayo de 1925, impulsado a hacerlo por la amenaza cierta de la disgregación del grupo y el cierre de la revista por las disputas internas (que llevó a la salida de Carlos A. Amaya) y la muerte de Ripa Alberdi. Si bien desde la cátedra, desde el 
cenáculo de estudios que conformó con sus discípulos y por medio de los discursos en banquetes y actos académicos fue brindando al grupo certezas de acción cultural que funcionaron como imperativos programáticos para el mismo, su dirección de la revista sinceraba su papel de Maestro del grupo, que sus permanentes escritos, críticas bibliográficas y editoriales en ella habían anticipado. La incorporación de Henríquez Ureña ese mismo año fortaleció a Renovación ya que el crítico dominicano fue uno de los más asiduos colaboradores de la revista con diversos ensayos sobre arte y literatura y de las puestas en escena teatrales, además de enriquecer con sus posicionamientos idealistas y latinoamericanistas los vínculos socráticos del grupo. Ya a partir de esta época, Guillermo Korn ocupó un rol más relevante aún en el grupo, no sólo por continuar con la dirección de la compañía teatral sino al participar asiduamente como ilustrador de Valoraciones y desempeñarse como el colaborar principal de su padre en su edición.

El resultado de estos cambios de dirección e incorporaciones en el grupo llevó a que en el bienio 1925-1926 Valoraciones alcanzase su mayor periodicidad con un total de 5 números. Pero a partir de 1926 el grupo Renovación perdió dinamismo comenzando el agotamiento de su propuesta cultural. Sin nuevas representaciones teatrales la compañía quedó inactiva y con la publicación esporádica de los últimos dos números de la revista (uno en 1927 y otro en el siguiente) y sin otros lanzamientos de su sello editorial, el grupo clausuraba su experiencia de extensión cultural en la ciudad. Sus últimos números dieron lugar a apuestas lúdico-heréticas como la publicación en su número 10 de 1926 de un Primer Salón de Escritores, a la que se prestaron con ganas diversos escritores (Oliverio Girondo, Leopoldo Marechal, Eduardo Mallea, Jorge Luis Borges y Ricardo Güiraldes), quienes impostando vocación de pintores enviaron dibujos diversos, entre los que destacaba como se aprecia en la Ilustración $\mathrm{n}^{\circ}$ 4, el dibujo de Arturo Costa Alvarez La libertad creadora (El Creador y su cría) en el que se retrataba a Korn junto a sus discípulos. ${ }^{10}$ En su número 12 de cierre publicaron Introducción a la metafísica de Bergson (traducción de Carlos María Onetti), presentada como un "obsequio especial a nuestros lectores" y toda una declaración de principios filosóficos. Renovación mostraba su regreso a fines de la década, a lo que había sido su punto de partida: un grupo discipular y un cenáculo de estudios que volvía a congregarse en torno al Maestro Korn y que la ilustración del profesor Costa Alvarez captó en su sentido profundo: un filósofo encumbrado de pie sobre el suelo fértil que su filosofía irrigaba y en el que crecían los discípulos portadores de su palabra. La publicación en 1930 por iniciativa de sus discípulos del libro que bajo el título Ensayos Filosóficos. Primer tomo. La libertad Creadora, reunió la mayoría de sus ensayos en una edición privada y fuera de comercialización, reafirmaba la voluntad socrática persistente por consolidar la formación intelectual del círculo discipular más que difundirlo en el mercado lector y su defensa de la acción creadora (Korn, 1930).

\footnotetext{
${ }^{10}$ La revista incluyó también un dibujo dedicado "a Valoraciones" del escritor futurista italiano Filipo Tommaso Marinetti quien había visitado el país en 1926 para brindar conferencias, entre ellas una en el Teatro Argentino de La Plata, el 19 de junio. Si bien el grupo Renovación y el mismo Alejandro Korn rechazaron al fascismo italiano, participaron por medio de Guillermo Korn (a quien Marinetti le obsequió el dibujo) en la "cena homenaje" que la revista vanguardista Martín Fierro le dedicó a su arribo a Buenos Aires, participación sólo posible porque los editores de la publicación porteña dejaron explícito que celebraban exclusivamente al escritor (Saítta, 1995: 161-169).
} 


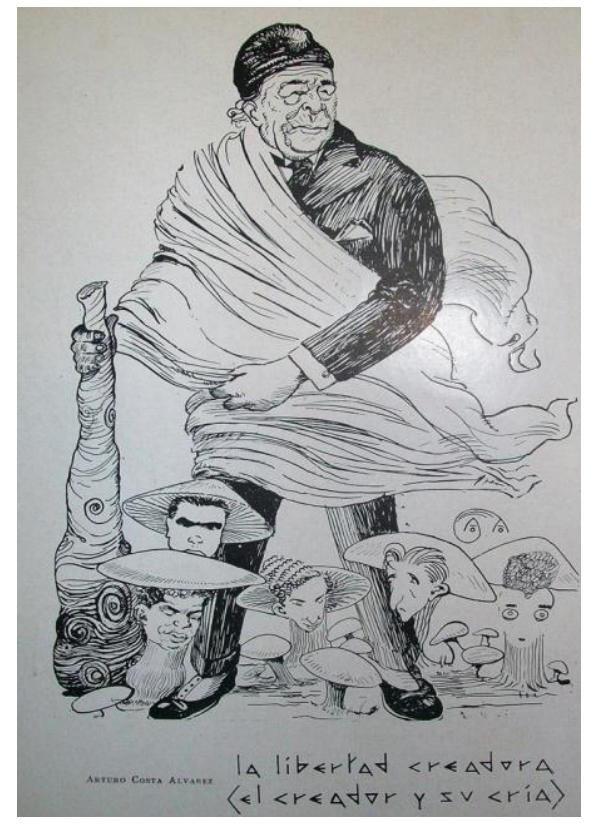

\author{
Ilustración nº 4: Alejandro Korn
}

Fuente: Valoraciones $\mathrm{n}^{\mathrm{o}} 10$.

\title{
V. Los instrumentos de la acción cultural en la ciudad politizados.
}

Ya en el contexto de una Argentina conmocionada por la clausura de la democracia, por la represión política, el fraude electoral y la crisis económica, los discípulos de Alejandro Korn relanzaron sus propuestas de extensión cultural de la década previa y fundaron en 1933 Teatro del Pueblo en Berisso, una localidad obrera del puerto de La Plata. La apuesta por un teatro político en los márgenes de la ciudad se debía a la incorporación del filósofo y de sus discípulos al Partido Socialista en 1931, sumándose desde la Federación Socialista Bonaerense a la acción cultural partidaria entre los trabajadores. Korn había cuestionado en duros términos la participación de profesores y de estudiantes en el golpe de estado de septiembre de 1930 que derrocó a Hipólito Yrigoyen, señalando que el régimen político que se instauraba con el general Félix Uriburu era una dictadura que conllevaría a la represión de los mismos universitarios. Su opinión sobre la situación nacional no se modificó durante la presidencia del General Agustín P. Justo (que se extendió entre 1932 y 1938), a quien interpretó como heredero de la dictadura y cuyo discurso del restablecimiento de la democracia se chocaba con la imposición del fraude electoral, el estado de sitio, la censura, la represión y las persecuciones a escritores, estudiantes y profesores de izquierda que jalonaron la vida cultural durante toda la década (Saítta, 2012: 245-310). En esa nueva coyuntura el grupo Renovación modificó radicalmente su acción intelectual. Si durante la década previa se había situado en el espacio cultural desde el cual tomaba posicionamientos políticos frente a los acontecimientos nacionales e internacionales, en estos años asumió un compromiso con un partido político desde el cual configuraría sus acciones intelectuales. Todas se desplegaron a partir de ese nuevo posicionamiento político: participación en actos socialistas, dictado de conferencias y cursos en sus centros y bibliotecas, publicación de escritos en la prensa partidaria (La Vanguardia y Revista Socialista) en un compromiso que incluyó también sus propias candidaturas a legisladores provinciales y nacionales. (Graciano, 2008: 139-204). Ya retirado de la cátedra en los años '30 Korn continuaba firmemente inscripto en posiciones filosóficas bergsonianas, como revelaba bien Apuntes filosóficos, su última obra publicada en vida por Claridad. Involucrado de lleno en las actividades culturales del Partido Socialista, elaboró para sus dirigentes y afiliados evaluaciones críticas del pensamiento filosófico europeo calificándolo como incapaz de formular nuevos sistemas de ideas que orientaran a la sociedad, debido a lo que consideraba formulaciones reaccionarias y de retorno al pasado. Ortega y Gasset, Bergson, Croce y 
Heidegger se revelaban a su entender incapaces de elaborar una nueva concepción eficiente del mundo (Korn, 1949: 473-500).

Berisso era un barrio que en sus características materiales y socioculturales era la contracara de la modernidad platense: sin trazado urbanístico de parques ni plazas, sin desarrollo edilicio público y privado planificado por el Estado, con escasos servicios escolares, sanitarios y de salud, de transporte, electricidad y agua; con calles de tierra y casas humildes de ladrillos, cartón, chapa y madera, no había sido alcanzado por el utopismo letrado del poder liberal en sus manifestaciones científicas y educativas (Vallejo, 2015). Mostraba el lado oscuro del desenvolvimiento de la Argentina agroexportadora, el de una comunidad obrera que concentraba a miles de trabajadores argentinos e inmigrantes (europeos, de medio oriente y africanos) sometida a la despiadada explotación laboral de los frigoríficos ingleses y norteamericanos y de la destilería de petróleo estatal YPF, a la represión de la policía conservadora y de los grupos parapoliciales de las empresas de la carne (Lobato, 2004: 41-68). El ocio en el Puerto estaba dominado por los bailes y fiestas organizadas por los centros y sociedades de fomento de los inmigrantes, por los clubes de fútbol amateurs y por los bares y prostíbulos, dejando un lugar limitado a las actividades culturales, restringidas a celebraciones de las asociaciones de inmigrantes, a la oferta del cine El Progreso y a las puestas teatrales irregulares de grupos filodramáticos de aficionados entre los que se destacaban algunos cercanos al anarquismo (Fos, 2010: 103120).

La nueva experiencia artística fue impulsada por Guillermo Korn y articulaba explícitamente la valoración iluminista del papel de los intelectuales en educar al Pueblo y el del teatro como un arte con una función ideológica emancipadora. Implicaba de ese modo introducir en su propuesta teatral la creencia socialista en el papel histórico de la clase obrera para transformar la realidad. Berisso como barrio obrero significaba para estos universitarios ahora socialistas, el espacio desde el cual construir con los trabajadores la fuerza política que diera un vuelco a la vida nacional, terminando con la dominación conservadora. El hijo del filósofo conocía la situación de precariedad social de los barrios obreros platenses ya que había sido concejal socialista de la ciudad y desde 1934 diputado nacional. Como legislador impulsó la conformación de una comisión de investigaciones parlamentarias para que estudiara el cumplimiento de las leyes laborales y evaluara las condiciones de trabajo y de vida de los trabajadores de la industria de la carne (República Argentina, Cámara de Diputados, 1936). Asimismo elaboró una crítica caracterización de la explotación capitalista y de la represión estatal en Berisso con los elementos del modernismo cultural que le posibilitaban la emancipación del obrero del futuro que imaginaba la poesía revolucionaria de Ernest Toller, la crítica humorística pero despiadada de la especialización y de la producción en serie de Tiempos Modernos de Charles Chaplin y la denuncia de las consecuencias humanas del trabajo "standar" de las novelas de sindicalistas comunistas como José Peter. Articulaba esos elementos con el discurso socialista de defensa de las leyes laborales y la socialización de los medios de producción como solución económica.

Para Guillermo Korn en Berisso el trabajo fabril y las enfermedades, los prostíbulos y el juego consumían la vida cotidiana de los trabajadores y de sus familias y sólo tenían acceso a lo que calificaba como "...manifestaciones bastardas del teatro y del arte 
mercantil..." (Korn, 1934: 230). Por ello era fundamental crear un centro teatral y artístico para brindarles una alternativa de divulgación cultural para su escaso tiempo libre que se articulara con la formación político-ideológica de los obreros. La compañía se convirtió en un grupo escénico integrado al Partido Socialista y contó con su apoyo material para montar los espectáculos. Estas condiciones de su desenvolvimiento llevaron a la compañía a innovar radicalmente sus escenarios de actuación, que pasaron a ser los locales de sindicatos, de sociedades de fomento, bibliotecas obreras y los actos socialistas, así como su público que pasaba a ser decididamente obrero. Modificó también su repertorio teatral al priorizar obras de temática política y también sus elencos, al integrarlos no sólo con universitarios y actores profesionales del teatro independiente, sino con trabajadores (Korn, 1934: 229-230). En una década en la que se consolidaban definitivamente el cine norteamericano y la radio comercial como industrias culturales, los escritores de izquierda como Alvaro Yunque, Elías Castelnuevo, Edmundo E. Barthelemy, Leónidas Barletta, Eugenio Navas y el mismo Guillermo Korn entre otros, publicitaban con mayor fuerza aún el papel cultural del teatro en la capacitación cultural y política del Pueblo o el proletariado. Estos escritores aunque reconocían el valor artístico de la radio y el cine y su potencialidad para la educación y capacitación política de los trabajadores, reafirmaban al teatro en el desempeño de esas funciones para la formación de las masas. El grupo escénico de Korn integraba así una serie de esfuerzos de teatro alternativo al "teatro burgués", como el Teatro del Pueblo de Leónidas Barletta, la Agrupación Artística Juan B. Justo y el Teatro de Arte Proletario. Eran expresión de un movimiento de afirmación de un teatro alternativo que desde la década del '20 fue promovido por escritores y teatristas de izquierda, desde revistas como Actualidad, Claridad y Nosotros y desde el socialismo y el comunismo (Saítta, 2003: 187-195). Pero el grupo escénico de Korn se diferenció de la propuesta de Barletta y se acercó más a la del Teatro de Arte Proletario y a la de la Agrupación Juan B. Justo, ya que fue una experiencia de teatro que montaba representaciones artísticas de izquierdas por componerse en parte por cuadros dramáticos obreros y destinar sus espectáculos a un público también obrero. Así su programa teatral había tomado el carácter de arte comprometido, lo que aparecía manifiesto por el contenido de sus obras y por los medios y contextos de concreción: la representación por actores proletarios y en círculos y manifestaciones políticas socialistas. Los trabajadores y militantes socialistas pudieron ver espectáculos del teatro clásico como La Posadera de Goldoni y moderno como Espectros y Casa de muñecas de Henri Ibsen. Así este tipo de apuesta escénica resignificó radicalmente la función del teatro que estos universitarios habían practicado en la década anterior, colocándolo al servicio del avance del socialismo y su programa expuso la tensión entre la obra de arte y su función política. Pero Guillermo Korn consciente de ella, reclamaba la autonomía de la obra teatral y su valoración estética ajena a toda consideración ideológica, afirmándola en las funciones teatrales, como revelaba el programa de Hinkemann de la Ilustración $\mathrm{n}^{\mathrm{o}} 5$ donde se citaba una expresión atribuida a Lenin con esa intención: "El teatro es necesario, no tanto para la propaganda, como para que los obreros puedan descansar de su trabajo diario". 



cuales predominaba la denuncia de las iniquidades y miserias sociales y la tragedia humana, producidas por el capitalismo con su violencia histórica que llevaba a la guerra.

Ilustración no 5: Programa de Hinkemann Fuente: Colección Programas Teatro del Pueblo.

El teatro de Korn representaba situaciones individuales como la tragedia de la mutilación de un hombre por las máquinas de matar y los sueños frustrados de riqueza de domésticas inmigrantes, a la vez que incursionaba en el drama colectivo de los chacareros italianos sin acceso a la tierra por el monopolio latifundista y retrataba las consecuencias nacionales de dominación político-económico, de explotación y miseria que el imperialismo petrolero producía en los pueblos de América Latina. Estas obras fundaban la acción artístico-política de la compañía y le posibilitaran llevar adelante la educación ideológica de la clase trabajadora. En ellas aparecía también la dimensión utópica socialista de su papel político como sujeto histórico destinado a crear el mundo nuevo. Esa era la utopía contenida en uno de los parlamentos del obrero socialista Pablo Vlasoff, personaje de La Madre, puesta en escena en conmemoración del $1^{\circ}$ de mayo de 1936 y que como se lee en el programa del espectáculo reproducido en la Ilustración $n^{\circ} 6$, en boca de un actor obrero exclamaba:

¡Queremos que los hombres se miren como hermanos y no como fieras! ¡Que las máquinas y la tierra pase a manos de los productores! ¿Queremos libertad, por ser ella la que ennoblece la vida! Para barrer con la esclavitud, la prostitución, el hambre y las cárceles, sólo hay un camino: la comunidad de toda la riqueza!

El parlamento atribuido a Vlasoff y la puesta en escena de La Madre (basada en la adaptación del escritor Eugenio Navas) buscaba deliberadamente y sin matices lograr que los espectadores y actores obreros identificaran como propia la realidad de explotación, de miseria y represión de los obreros que recreaba. Los elementos narrativos, estéticos e ideológicos puestos en juego por Gorki con su lenguaje realista, el escenario fabril y la explotación laboral, los personajes obreros revolucionarios, la represión policial y 
gubernamental y las madres proletarias dispuestas a cualquier sacrificio en la defensa del ideal socialista de sus hijos (que también abrazó), posibilitaban esa identificación directa con el sufrimiento obrero provocado por el capitalismo, que era así universal y cuya única solución la brindaba el socialismo. La dramatización teatral generaba una identidad social, ecológica y política entre la comunidad obrera rusa imaginada en la novela y la integrada por los obreros del puerto de La Plata, para quienes, al igual que para la madre en su trágica muerte final, la salida se encontraba en el socialismo. Y al igual que los personajes de Gorki, los universitarios de Teatro del Pueblo creían en la inmanencia redentorista de los libros, como portadores de la verdad sobre las injusticias del capitalismo e instrumento de la cultura para la toma de conciencia revolucionaria de los trabajadores. ${ }^{11}$

Ilustración no 6: Programa de La Madre, de Máximo Gorki

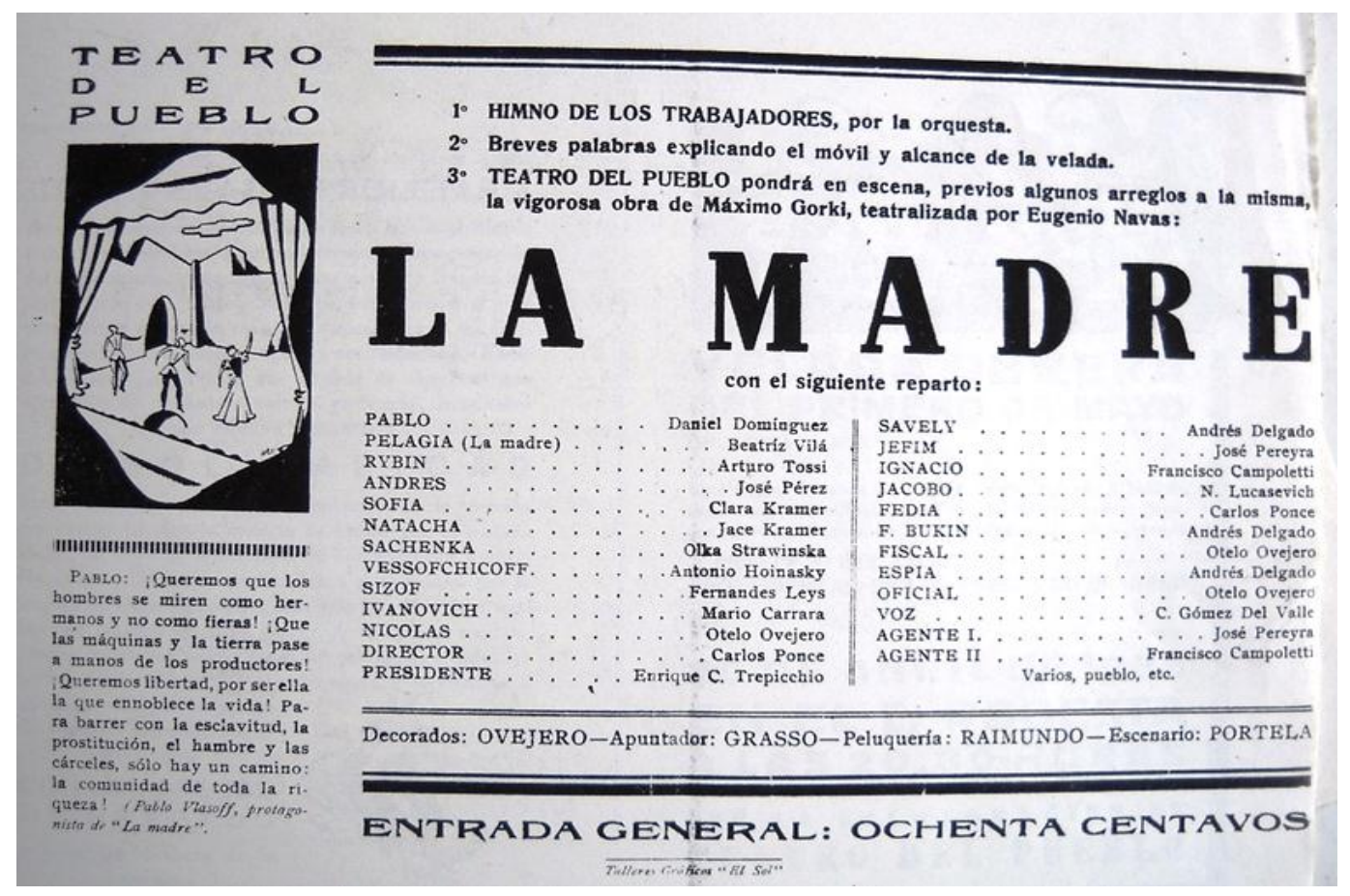

Fuente: Colección de Programas de Teatro del Pueblo.

\footnotetext{
${ }^{11}$ Como señaló el poeta Juan Gelman (1998) La Madre fue una lectura obligada de todas las izquierdas del mundo a lo largo del siglo XX y sin dudas el voluntarismo revolucionario iluminista que profesaba fue una de sus razones. En Argentina fue llevada a escena por muchas de las compañías teatrales de izquierda e independientes y circuló en el país en diversas ediciones de libros.
} 
La deriva hacia la politización de sus iniciativas culturales en los años '30 fue evidente también en la propuesta de fundar una revista socialista. Pero su postura doctrinaria por un socialismo idealista (expresado en su título, Fabiana) que debía abrir un debate partidario contra el marxismo, llevó sin embargo al propio Alejandro Korn a desautorizar su publicación. Esa politización también impuso al grupo a optar ya no por la difusión de diversas propuestas de la plástica como había sucedido en la década anterior, sino por la promoción de una comprometida con el socialismo. En efecto, al mismo tiempo que llevaban adelante el Teatro del Pueblo, estos universitarios impulsaron desde la Federación Socialista Bonaerense el arte mural en la ciudad y promocionaron al artista plástico Francisco Américo De Santo (egresado de la Escuela de Bellas Artes platense) para su concreción. Militante socialista y de condición obrero, De Santo colaboró con las escenografías de la compañía teatral y creó diversos murales en los barrios de la ciudad, decorando también con pinturas murales de temática proletaria la Casa del Pueblo de La Plata: mientras en su hall aparecía El Trabajo, un tríptico que representaba a los trabajadores del campo, la ciudad y el puerto, su interior había sido decorado con otro titulado El trabajo en el puerto como se reproduce en la Ilustración $n^{\circ}$ 7. En el manifiesto artístico que el grupo dio del muralismo de De Santo, se lo definió como la forma consagrada que tomarían las artes plásticas en una sociedad socialista: un arte social de apropiación colectiva y de temáticas proletarias, opuesto al "cuadro de caballete", manifestación artística del individualismo burgués y de disfrute privado por su condición de mercancía. Sostenían:

El arte social vuelve a encontrar el antiguo aliento de vida en contacto con el pueblo en la decoración audaz de grandes ámbitos cerrados o abiertos, donde vibre la acción y el entusiasmo colectivos: Casas del Pueblo, Estadios, Bibliotecas, Teatros [...] Las pinturas de De Santo son una muestra de las posibilidades del arte en la sociedad del futuro que el Socialismo forja con esfuerzo heroico y perseverante. (Korn, 1935: $\mathrm{n}^{\circ}$ 285)

Ilustración no 7: El Trabajo, pintura de Francisco de Santo. Fuente: Claridad Año XIII, enero $1935, \mathrm{n}^{\circ} 285$

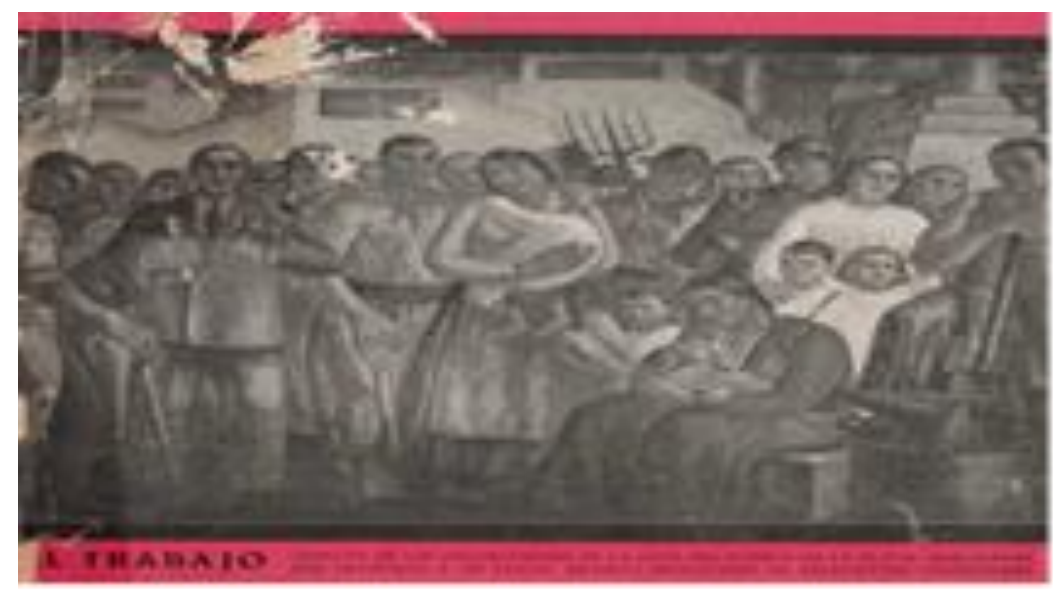


Era visible en esa definición la influencia del muralismo, en un momento en que además tuvo gran difusión por la visita de David Alfaro Siqueiros al país en 1933, propuesta que también interesaba a otros pintores argentinos cercanos al comunismo como Lino Eneas Spilimbergo, Antonio Berni y Juan Carlos Castagnino. Los murales de la Casa del Pueblo de De Santo recreaban escenas del trabajo obrero en los puertos, en el campo y en la fábrica, resaltando las figuras encorvadas por el esfuerzo y el agotamiento físico de los trabajadores y a la vez su condición de productores sociales. Una temática estrictamente obrera que apostaba por la técnica del realismo en la composición, sin innovaciones de materiales o en el uso de instrumentos. Sus otros murales se ubicarían en los suburbios populares de La Plata y todos tuvieron como temática el descubrimiento artístico de sus habitantes: Niños en Juego y Los inmigrantes en Berisso, Los pescadores en Ensenada, El Sembrador en Los Hornos. El muralismo promovido por el Partido Socialista aparecía como una apropiación, en parte reflejo, de la que los artistas comunistas mexicanos como Siqueiros y Diego Rivera realizaron en su país y difundían en América Latina. Sin embargo, los universitarios socialistas podían reclamar su conocimiento directo del movimiento artístico mexicano y su apropiación a través de Vasconcelos y Henríquez Ureña. Además, en su reivindicación de los rasgos técnicos y artísticos del muralismo socialista asomaba una propuesta estética que los distanciaba de la vertiente de pintores comunistas: mientras los murales de De Santo eran realizados en instituciones partidarias y públicas, las obras de influencia mural de Berni no dejaban de ser grandes pinturas de "caballete" y la que Siqueiros realizó en Buenos Aires denominada Ejercicio Plástico junto a un grupo de pintores de izquierda (Spilimbergo, Berni, Castagnino entre otros), adolecía según aquellos de las características del arte burgués: carecía de temática proletaria, había sido el encargo de un rico empresario dueño de un diario y decoraba, para usufructo estético privado, las paredes del sótano de una de sus propiedades. En esa confrontación el arte de Francisco De Santo en la prensa partidaria y en el Teatro del Pueblo adquiría la dimensión del artista que forjaba el arte de la sociedad futura colectivizada. Así, el programa teatral de Hinkemann de 1935 (puesta en escena realizada en el marco del congreso partidario socialista) interpelaba a sus espectadores con afirmaciones que definían al muralismo como la forma del arte del futuro en la nueva sociedad: "La pintura mural de gran tamaño será la principal forma de este arte dentro de una sociedad socialista” (Colección Programas Teatro del Pueblo).

La experiencia del Teatro del Pueblo puso en tensión lo que consideraban tareas sociales del teatro y que sus comedias y dramas podían concretar: la educación del gusto estético de las masas y su adoctrinamiento ideológico a través de la propaganda y la 
denuncia social. Teatro de arte y teatro político se conciliaban según su director, para reemplazar a "las manifestaciones bastardas del teatro y del arte mercantil..." (Korn, 230), en una acción cultural desalienante de los trabajadores. La agrupación artística dio lugar durante tres años, a la vinculación entre obreros y universitarios socialistas, actores y escenógrafos del teatro independiente, en una inédita interacción en sus diversas puestas en escena. La cultura estética promovida por el grupo de Alejandro Korn dentro del socialismo no se alejaba sin embargo de la concepción crociana del arte practicada por Renovación en la década del '20, aunque la conciliaba con su politización al ser los trabajadores y su emancipación social el fin último de esta experiencia artística. Esta propuesta teatral se sostuvo también en la tesis del necesario compromiso político de los intelectuales con los trabajadores, de su papel fundamental en su formación ideológica y de asumirse como su dirección política, como revelaba el mural reproducido de De Santo, simbolizando la figura de estos universitarios con un hombre de traje y libro en mano, que interpelaba con su mirada y su gesto a quienes "vivieran" esa experiencia estética.

Si en los años '20 su labor cultural se orientó a difundir iniciativas artísticas resignificantes de sus experiencias subjetivas, en los años '30 esa labor asumía un propósito emancipatorio clasista. Para el hijo del filósofo la acción cultural y política del socialismo posibilitaría la liberación de la capacidad creadora del pueblo terminando con la explotación y la alienación del sujeto, reconciliando arte y vida y a los artistas y el pueblo: “...cuando una sociedad socialista promueva en todos los órdenes de la vida pública el acercamiento efectivo de los artistas y el pueblo, facilitando la libre expansión de tantas energías creadoras que hoy permanecen latentes pero estériles en medio de la injusticia y el rigor del capitalista" (Korn, 1935: $\mathrm{n}^{\circ}$ 285). Sin embargo la experiencia del Teatro del Pueblo finalizaría de modo violento: la policía del gobernador Manuel Fresco que había iniciado una campaña de persecución de las izquierdas en la provincia, irrumpió durante una función de la compañía teatral y encarceló a su director y actores, un sábado 19 de septiembre de 1936. Sólo tres semanas después, con la vigilia de familiares, discípulos y colegas fallecía en su casa Alejandro Korn.

\section{Una comunidad socrática en la polis moderna}

En la oración fúnebre ya citada que Henríquez Ureña le dedicó a Korn, definió su labor filosófica como la de un creador de "...comunidades socráticas, donde prenden doctrinas generosas de influencia perdurable." (Claridad, 1936: $\mathrm{n}^{\mathrm{o}}$ 306-307). Su definición atinaba en lo medular de la acción intelectual de su colega y amigo ya que durante su docencia universitaria había conformado grupos de estudiantes y colegas que desplegaron diversas iniciativas culturales y continuaron con ellas al incorporarse al socialismo. El profesor dominicano acertaba también al señalar que la labor de Korn como filósofo se había orientado por valores para construir los "destinos de América como futura Patria de la justicia..." (Ibíd). Sin embargo, la prensa periódica como muchos de los colegas que lo evocaron en su muerte, prefirieron abundar en la imagen socrática de la agonía de Korn y la propia Universidad platense la reforzó con el encargo de un cuadro que rememoró el momento de su brindis final rodeado de colegas y discípulos, en una alusión directa a La muerte de Sócrates de Jacques Luis David. Esta asociación se fundamentó 
también en tempranos trabajos académicos como el de Rodríguez Alcalá quien desarrolló la tesis del socratismo en la práctica filosófica de Korn (Rodríguez Alcalá, 1954: 229-245).

No era que no reconocieran su influencia en los cambios en la enseñanza académica de la filosofía, en la profesionalización de la disciplina, en la orientación de los universitarios y en las experiencias culturales aquí analizadas, pero prefirieron destacar el gesto socrático de su despedida de la vida. Pero a diferencia de la del filósofo griego su muerte sucedió sin ninguna acusación pública que cuestionara su papel en la cultura argentina como impiadoso o corruptor de la juventud. Esa acusación cayó en realidad sobre sus discípulos, bajo la forma de la represión y censura que por agitadores políticos les aplicó el Estado, por promover una democracia política y social para el país. Mostraba bien que la persecución ideológica contra los intelectuales de izquierda por parte de los poderes públicos en un mundo marcado por el auge de los fascismos europeos aplicando el estado de excepción, era una política en ascenso en esos años (Agamben, 2005). En verdad la ceremonia del brindis que realizó Korn en su final pocos días después del cierre del Teatro del Pueblo tenía otra significación y ella era política. Con ese acto les dejaba no sólo un mensaje de celebración de la vida que lo abandonaba y que bien hubiera compartido Zaratustra, sino también de reivindicación de su compromiso con la cultura y el socialismo, para no cejar en su lucha creadora. Era el gesto de comunicación socrática de un hombre que había perdido la voz a causa de la enfermedad que lo llevó a la muerte. La enseñanza final de un Maestro de la Argentina que se había situado en esos años '30 como partícipe de las disputas del ágora argentino, tensionado por el autoritarismo conservador dominante en el país y que reconoció también su propia limitación para formular una nueva Weltanschauung frente a la crisis cultural occidental de entreguerras.

Fue otra vez Henríquez Ureña quien en esa despedida final, volvió a acertar con su juicio sobre la tarea de Korn como pensador, reconociendo que su concepción filosófica había sido decisiva para la acción cultural y política de sus discípulos de Renovación en esa época histórica de crisis, revoluciones, autoritarismos y guerra. Para el dominicano esa nueva concepción del mundo ansiada por el filósofo se había desplegado a partir de sus postulados de la acción libre y creadora de los ciudadanos, por realizar valores de libertad, de solidaridad e igualdad, que en la formulación siempre latinoamericanista de Ureña, los había sintetizado tempranamente en sus escritos de los años '20 como la utopía de una América como Patria de la justicia para la humanidad y no podía ser de otro modo ya que también había participado y contribuido a ese esfuerzo. ${ }^{12}$ Alejandro Korn abandonaba para siempre la ciudad que en su fallido sueño de metrópolis nacional y en su conversión en "ciudad universitaria", les había ofrecido a ambos la posibilidad de una experiencia de sociabilidad intelectual en las largos diálogos con sus estudiantes a que daban lugar las caminatas por sus calles y parques y que, a la vez que constitutivas de su labor en la cátedra, eran acordes a sus propuestas de un humanismo idealista que convertía a la urbe en su ámbito de realización. En la tradición del arielismo de Rodó, Korn con su prédica

\footnotetext{
${ }^{12}$ Sus escritos La Utopía de América y Patria de la Justicia (publicados en la revista platense Estudiantina en 1925) coincidían con los valores idealistas postulados por Korn entre sus discípulos (Henríquez Ureña, 1978 [1925]: 3-11).
} 
filosófica, había pacientemente sustentado durante dos décadas una comunidad socrática que intervino con su acción cultural en la polis argentina de entreguerras.

\section{Bibliografía}

Agamben, Giorgio (2005). Estado de excepción. Buenos Aires, Adriana Hidalgo editora. Agulhon, Maurice (2009). El círculo burgués. La sociabilidad en Francia, 1810-1848. Buenos Aires, Siglo XXI Editores. Barbusse, Henri (1924). Fatalidad. La Plata, Editorial Renovación, La Plata. Biagini, Hugo (1995). La Huelga Grande de La Plata, Todo es Historia, 330, 17-35. -------. (Comp.). (1999). La Universidad de La Plata y el Movimiento Estudiantil. Desde sus orígenes hasta 1930. La Plata, Editorial de la UNLP. --------. (2000). La Reforma Universitaria. Antecedentes y Consecuentes. Buenos Aires, Leviatán. Buchbinder, Pablo (1997). Historia de la Facultad de Filosofía y Letras. Universidad de Buenos Aires, Buenos Aires, Eudeba.

Colección Programas Teatro del Pueblo de Puerto La Plata. La Plata, UPAK. Coll Cárdenas, Marcelo (2005). La Universidad Nueva entre 1897 y 1955, en Barba, F. (Dir.) La Universidad de La Plata en el Centenario de su nacionalización (pp. 25-101). La Plata, UNLP. Chejov, Antón (1924) Relato de un desconocido. La Plata, Editorial Renovación.

Eujanian, Alejandro (2001). El novecentismo argentino: reformismo y decadentismo. La revista Cuaderno del Colegio Novecentista, 1917-1919, Estudios Sociales. Revista Universitaria Semestral, Año XI, 21, Santa Fe, Argentina, Universidad Nacional del Litoral, segundo semestre, 83 - 105.

Fos, Carlos (2010). En las Tablas libertarias. Experiencias de teatro anarquista en Argentina a lo largo del siglo XX. Edición y Compilación Lorena Verzero. Buenos Aires, Atuel.

Gelman, Juan (1998). Enigmas, Página 12, domingo 20 de septiembre de 1998. Recuperado de http://www.pagina12.com.ar/1998/98-09/98-09-20/index.htm Accedido: 4/2/2016.

Gorelik, Adrián (2010). La grilla y el parque. Espacio público y cultura urbana en Buenos Aires, 1887-1936, Bernal, Universidad Nacional de Quilmes.

Graciano, Osvaldo (2008). Entre la torre de marfil y el compromiso político. Intelectuales de izquierda en la Argentina, 1918-1955. Bernal, Universidad Nacional de Quilmes.

Hale, Charles (1991). Las ideas políticas y sociales en América Latina, 1870-1930, en Bethell, L., (ed.). Historia de América Latina. América Latina: cultura y sociedad, 1830-1930 (1-64). Barcelona, Crítica.

Halperín Donghi, Tulio (2000). Vida y muerte de la República verdadera (1910-1930). Buenos Aires, Ariel.

Henríquez Ureña, Pedro (1978) [1925]. La Utopía de América, en Henríquez Ureña, Pedro La utopía de América. Prólogo de Rafael Gutiérrez Girardot. Compilación y cronología: Ángel Rama y Rafael Gutiérrez Girardot (3-8), Caracas, Biblioteca Ayacucho.

---------. (1978) [1925]. Patria de la Justicia, en Henríquez Ureña, Pedro La utopía de América. Prólogo de Rafael Gutiérrez Girardot. Compilación y cronología: Ángel Rama y Rafael Gutiérrez Girardot (8-11), Caracas, Biblioteca Ayacucho.

Korn, Alejandro (1918). "Incipit vita nova", Atenea. Letras-Artes-Filosofía. Publicación Bimestral de la Asociación de ex alumnos del Colegio Nacional de La Plata, 1918, Año I-Volumen I, marzoabril, $n^{\circ}$ I, 9-14.

-------. (1920). La Libertad Creadora, Verbum, Revista del Centro de Estudiantes de Filosofía y Letras, Año XIV, Junio-julio n ${ }^{\circ} 54,135-161$. 
- (1920). La libertad Creadora. Buenos Aires, Imprenta Araujo Hnos.

- (1922). La Libertad Creadora. La Plata, Editorial Renovación.

- (1930). Ensayos Filosóficos. Primer Tomo, La Libertad Creadora. La Plata, Talleres Gráficos Olivieri y Domínguez.

. (2011) [c. 1918]. Lecciones de historia de la filosofía c. 1918. Transcripción y Edición Clara Alicia Jalif de Bertranou. Mendoza, Facultad de Filosofía y Letras UNCuyo/ Instituto de Filosofía Argentina y Americana-IFAA.

---.--. Filosofía contemporánea. Alejandro Korn: lecciones inéditas, 1925. La Plata, 2012.

---------. (1949) [1917.] Corrientes de la Filosofía contemporánea, en Korn, Alejandro Obras Completas (pp. 345-363), Buenos Aires, Claridad.

-------. (1949). Obras Completas, Buenos Aires, Claridad.

Korn, Guillermo (1934). El teatro del pueblo de Puerto La Plata, Anuario Socialista. Buenos Aires, La Vanguardia, 229-230.

--------. (1935). Las pinturas decorativas de Francisco A. De Santo para la Casa del Pueblo de La Plata, Claridad. Revista de Arte. Crítica y Letras. Tribuna del Pensamiento Izquierdista. Buenos Aires, año XIII, enero de 1935, nº 285.

-------. (1963). El teatro del grupo "Renovación", en AAVV, Universidad "Nueva” y Ámbitos culturales platenses (275-290). La Plata, UNLP.

Korn, Inés (1960) Alejandro Korn, mi padre. Córdoba, Universidad Nacional de Córdoba, Facultad de Filosofía y Humanidades.

Lobato, Mirta Zaida (2004). La vida en las fábricas. Trabajo, protesta y política en una comunidad obrera, Berisso (1904-1970). Buenos Aires, Prometeo.

Orfila Reynal, Arnaldo (1943). Alejandro Korn. Argentino ejemplar. Bahía Blanca, Colegio Libre de Estudios Superiores.

Rama, Ángel (1998). La ciudad letrada. Montevideo, Arca.

Ranea, Alberto Guillermo (2002). Una biblioteca y su sombra, 1916-1936: la vida intelectual de entreguerras en el reflejo de los libros y el pensamiento de Alejandro Korn, Saber y Tiempo, Revista de Historia de la ciencia, volumen 4, no 14, 119-136.

Real de Azua, Carlos (1985). Prólogo a Rodó, José Enrique (1985). Ariel. Motivos de Proteo (pp. IX-XXXV) de Venezuela, Biblioteca Ayacucho.

República Argentina, (1916). Tercer Censo Nacional, Tomo I, Antecedentes y Comentarios, Buenos Aires, Talleres Gráficos L. J. Rosso y Cía.

República Argentina, (1936). Cámara de Diputados. Comisión Legislación del Trabajo, Expediente 513-D-1936 nº 24, 24 de septiembre de 1936, Buenos Aires, Imprenta del Congreso Nacional.

Ripa Alberdi, Héctor (1925). Obras. La Plata. Grupo de Estudiantes Renovación.

Rodó, José Enrique (1985). Ariel. Motivos de Proteo. Prólogo de Carlos Real de Azua, Venezuela, Biblioteca Ayacucho.

Rodríguez, Fernando Diego (1999). Inicial, Sagitario y Valoraciones. Una aproximación a las letras y la política de la nueva generación americana, en Saúl Sosnowski (ed.) La cultura de un siglo. América Latina en sus revistas (pp. 217-247). Buenos Aires, Alianza.

Rodríguez, Fernando Diego, \& Vasquez, Karina (2002). Gritos y susurros en el Jardín de Akademos. El movimiento estudiantil reformista en La Plata a través de sus revistas (1923-1927), Intellèctus, Revista Eletrônica, Ano I, no 2.

Rodríguez Alcalá, Hugo (1954). El socratismo de Alejandro Korn, Research Studies of the State College of Washington, volumen XXII, 229-245.

Sánchez Distasio, Alicia (2005). La Plata (1886-1956), en Pellettieri, Osvaldo (Director). Historia del Teatro Argentino en las provincias (pp. 45-86), Buenos Aires, Galerna. 
Saítta, Sylvia (1995). Marinetti en Buenos Aires. Entre la política y el arte. Cuadernos Hispanoamericanos, 539-540, 161-169.

(2003). La dramaturgia de Elías Castelnuovo: del teatro social al teatro proletario, en Pellettieri, Osvaldo (ed.). Escena y Realidad (187-195). Buenos Aires, Galerna.

--------. (2012). La cultura, 1930-1960, en Cattaruzza, Alejandro (comp.). Argentina. Mirando hacia adentro, tomo IV. 1930/1960, (245-310), América Latina en la historia contemporánea, Madrid, Fundación Mapfre-Taurus.

Terán, Oscar (1986). La libertad tolerante de Alejandro Korn, en Terán, Oscar En busca de la ideología argentina (pp. 179-194). Buenos Aires, Catálogos.

Torchia Estrada, Juan Carlos (1985). Alejandro Korn ante el positivismo, en Biagini, Hugo E. (Comp.). El movimiento positivista argentino (pp. 431- 449). Buenos Aires, Editorial de Belgrano.

----... (1986). Alejandro Korn Profesión y vocación. México, UNAM.

---------- (2011). Introducción, en Korn, Alejandro (2011). [c.1918]. Lecciones de Historia de la Filosofía c. 1918 (15-41). Transcripción y Edición Clara Alicia Jalif de Bertranou. Mendoza, Facultad de Filosofía y Letras UNCuyo/ Instituto de Filosofía Argentina y Americana-IFAA.

--------. (2011). Tres lecciones inéditas de Alejandro Korn sobre Historia de la Filosofía, en Cuyo. Anuario de Filosofía Argentina y Americana, 2011, volumen 28, 145-191.

Vallejo, Gustavo (1999). El culto de lo bello. La universidad humanista de la década del '20, en Biagini, Hugo E. (Comp.). La Universidad de La Plata y el Movimiento Estudiantil. Desde sus orígenes hasta 1930 (pp. 113-152). La Plata, Editorial de la UNLP.

--------. (2007). Escenarios de la cultura científica argentina. Ciudad y universidad (18821955). Madrid, CSIC.

----------. (2015). Proyecto urbano y sectores populares en la génesis de La Plata. Rosario, Prohistoria ediciones.

\section{Periódicos}

El Argentino.

El Día.

La Vanguardia.

\section{Revistas}

Claridad. Revista de Arte, Crítica y Letras. Tribuna del pensamiento izquierdista, 1926-1941.

Valoraciones. Humanidades. Crítica y Polémica. La Plata, 1923-1928 